Témoigner Témoigner. Entre histoire et mémoire

Getuigen Revue pluridisciplinaire de la Fondation Auschwitz

$118 \mid 2014$

Au nom des victimes. Dictature et terreur d'État en Argentine, Chili et Uruguay

\title{
Een theatraal memorandum
}

Mémorandum théâtral

A theatrical memorandum

Isabelle Galichon

URL : http://journals.openedition.org/temoigner/1242

DOI : $10.4000 /$ temoigner. 1242

ISSN : 2506-6390

Éditeur :

Éditions du Centre d'études et de documentation Mémoire d'Auschwitz, Éditions Kimé

Édition imprimée

Date de publication : 1 octobre 2014

Pagination : 27

ISBN : 978-2-84174-674-3

ISSN : 2031-4183

Référence électronique

Isabelle Galichon, «Een theatraal memorandum », Témoigner. Entre histoire et mémoire [Online], 118 |

2014, Online op 01 octobre 2015, geraadpleegd op 23 octobre 2020. URL : http://

journals.openedition.org/temoigner/1242 ; DOI : https://doi.org/10.4000/temoigner.1242

Tous droits réservés 


\section{LO REAL VOLGENS ISRAEL GALVÁN}

OP DE SCENE Een unieke choreografie een lichamelijke en spirituele oefening, een verhaal zonder woorden over de vervolging van de zigeuners.

adat hij in Sevilla de opvoering van Aren bijwoonde, een voorstelling met zes choreografieën over stierengevechten, beschreef eorges Didi-Huberman de dans van Israe Galván als een 'dialectiek van de montage': 'Hij zoek een handeling die de gruwelijke hakbeweging, de genadeslag, kan verzoenen met de sierlijkheid van een dan Pf een dynamiek' (vertaald uit Le danseur des solitudes, Larijs. Mel/The Real, verdiept Israel Galván zict, Lo Real/ Le Réell he Real, verdept volging en uitroeiing van de gitanos tijdens de Tweede Wereldoorlog en knoopt hij zo aan bij de dramatische spanning die, opnieuw volgens Didi-Huberman, aan er datloss er datlosstij abstracte tijd waarin hij El final de este estado de cosas redux situeert, zijn laatste werk over de Apocalyps van de reäle, historische tijd. Hij breekt met de eenzen in de reêle, historische tijd. Hij breekt met de eenzaambrengt zowel zijn licham als zijn kunst terug tot de brengt zowel zijn lichaam als zijn kunst terug tot de essentie: een pure vorm voor 'een gemeenschappelijke die zijn kinderijd haben be heert, en gat de die zijn kindertijd hebben beheerst, en gaat de uitdagreng . Weinig kunstar he brengen. Weinig knnstenis hen zich tot dusver gewaagd aan deensceneringvan de zigeunerdeportatie. De bailare de Sevill overtuigende manier om het geweld uit te beelden sing ligt in de kunst zelf: alleen de flaning. Deoplossing ligt in de kunst zelf. alleen de flamencodans, al zitdrukkingvan het geheugen en de virtuositeit van het al va Al vanaf de proloog, 'Se corta el aire', herkennen

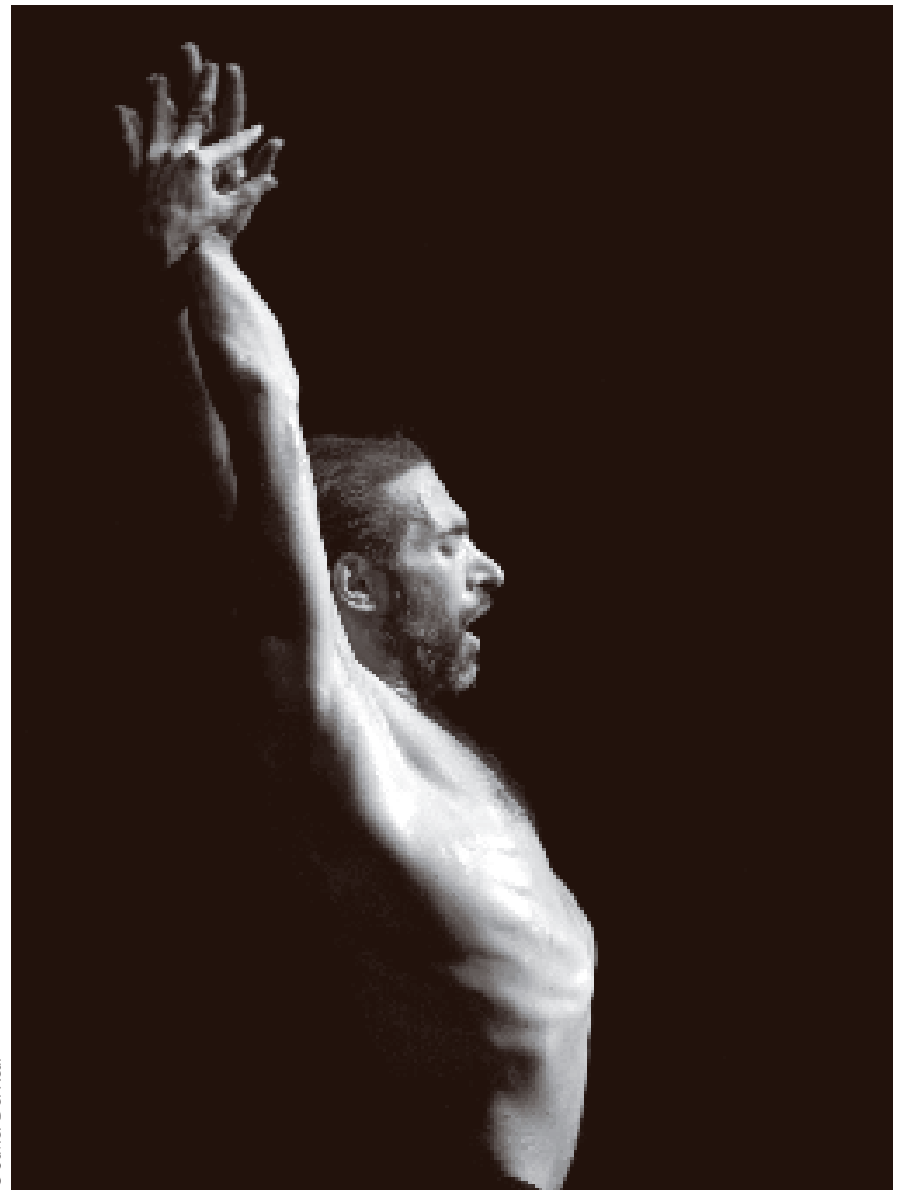

reert. Met dat verschil dat we geen temple ${ }^{1}$ zien, geen gehouden gebaren of lang uitgerekte bewegingen De danser strekt zijn arm en doorklieft de ruimte: zijn hand maakt geen sierlijke kronkels maar vormt een perfecte lijn, als een vlijmscherp mes. In één krachtige beweging geselt hij de lucht, de ruimte, de werkelijkheid, lo real. Niet om een ultieme betekenis te zoeken, maar om te zien wat er overblijft. In de stilte van deze scène veroorzaakt één enkele beweging een explosie van energie. De kille soberheid van het eerste deel ruint dan plaats voor een vrijere en meer diverse scenten dat het

Lo Real volgt geen narratieve structuur: het is veelar bres wisselen af met de laína, die typische passionele flamencostem metscherpe uithalen in de hogere registers. Beetje bij beetje verkleinen de zangers de cirkel

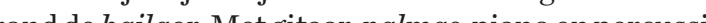
brene ( in my heart (Anthony and the Johnsons) en spelen ze

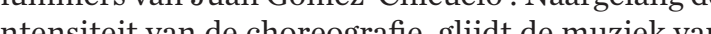
the cho hetlanentovandecant

meer bepaald het filmische beeld, maakt everits nieuwe scin a k Canta Gitano van Tony Gatlif en wo from Canta Gitano van Tony Gatif, en wordt er verwezen naar Tlefland, waarin Leni Riefenstahl zigeuners liet men is wel een man is wel een ma de representatie pang

Twee passages zijn werkelijk magistraal: Israel Galvan die 'de trein' danst op een metalen plaat, die het bezeten in de zaal, en Is taconeos luid doet weerklinken in de zaal, en Isabel Bayon die Leni Riefenstahls interpretatie var Carmen imiteert en zo crëert een dramatische spannings moakt. Galván kijker geboeid tot de laatste scène, wann en hij kijker geboeid tot de lotste scène, wanneer hij panemo ving het publiek a swijst. De wetkelijkhe meft

Isabelle Galichon

$\rightarrow$ Meer info

$\Delta$ Lo real/Le réel/The rea Een productie van het Teatro Real van Madrid, in coproductie met het Parijse Théâtre de la Ville. Dansers: Israel Galvan, Belen Maya en Isabel Bayon Dilaar : Juan Gomez 'Chicuelo' Dans, zang en jaleos : Caracafé, Bobote en Uchi $\diamond$ Torobaka, het nieuwste stuk van Israel Galván en Akram Khan, gaat in première in België op 8 oktober 2014 (Concertgebouw Brugge), in het Verenigd Koninkrijk op 3 november 2014 (Sadler's Wells, Londen) en in Nederland op 2 februari 2015 (Stadsschousburg Amsterdam). Het zal ook nog te zien
zijn in Parijs vanaf 16 december 2014 (Thêatre de la Ville). (1) Term uit de stierengevechten : langzame beweging van de matador
naar de stier.

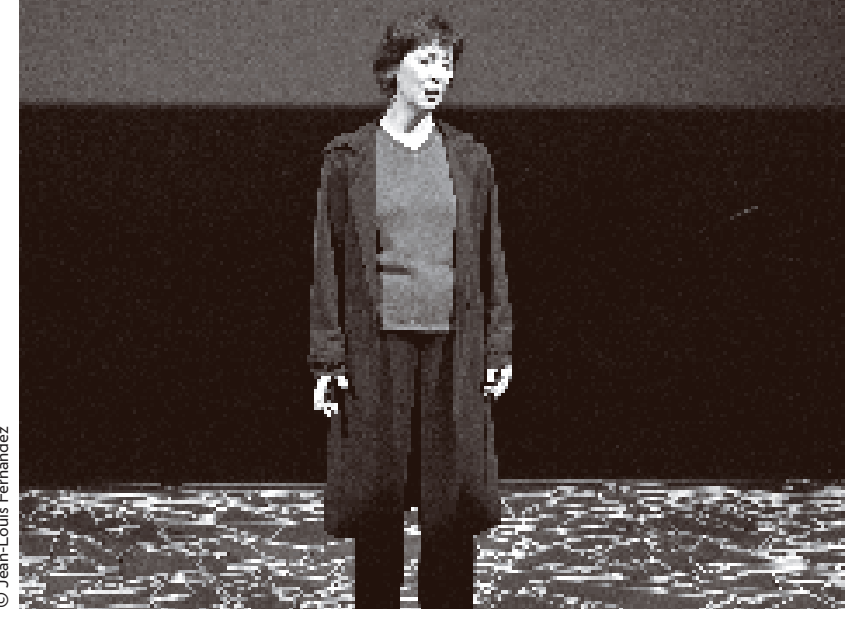

EEN THEATRAAL MEMORANDUM

an 13 maart tot 17 mei 2014 bracht het Théâtre de l'Atelier uit Parijs Femme non-rééducable. Mémorandum théâtral sur Anna Politkovskaïa van Stefano Massini, in een regie van Arnaud Meunier en met Anne Alvaro in de titelrol. Het is een stuk over herinnering - die naar boven komt in de soms onsamenhangende en fragmentarische tekst, en wordt gedragen door het verhaal van de getuige. Het spel is minimalistisch. De herinnering wordt slechts belichaamd door twee stemmen en een viool: het is Anna Politkovskaja's verhaal, haar getuigenis, die in scène wordt gezet. Het decor is spookachtig met alleen de subtiele belichting en een vervallen gebouw op de achtergrond.

Het theater biedt hier nieuwe perspectieven vor de representatie van herinnering en getuivoor de representatie van herinnering en getui-
genis. De tekst zelf is niet van Anna Politkovskaja, maar is een (re)constructie van Massini. Isabelle Galichon 